University of Washington Tacoma

UW Tacoma Digital Commons

$11-25-2019$

\title{
Sexual and Relationship Violence Prevention and Response: What Drives the Commuter Campus Student Experience?
}

\author{
Erin Casey \\ University of Washington Tacoma, ercasey@uw.edu \\ Sarah Cote Hampson \\ University of Washington Tacoma, hampsons@uw.edu
}

Alissa R. Ackerman

Follow this and additional works at: https://digitalcommons.tacoma.uw.edu/socialwork_pub

\section{Recommended Citation}

Casey, E. A., Hampson, S. C., \& Ackerman, A. R. (2019). Sexual and Relationship Violence Prevention and Response: What Drives the Commuter Campus Student Experience? Journal of Interpersonal Violence, 0886260519888188. https://doi.org/10.1177/0886260519888188

This Article is brought to you for free and open access by the Social Work \& Criminal Justice at UW Tacoma Digital Commons. It has been accepted for inclusion in Social Work \& Criminal Justice Publications by an authorized administrator of UW Tacoma Digital Commons. 
Sexual and Relationship Violence Prevention and Response: What Drives the Commuter Campus Student Experience?

KEY WORDS: sexual assault, intimate partner violence, campus, prevention, commuter

Corresponding Author:

Erin A. Casey, MSW, PhD

University of Washington, Tacoma

Social Work Program

1900 Commerce Box 358425

Tacoma, WA 98402

253.692.4524

ercasey@u.washington.edu

Sarah Cote Hampson, PhD

University of Washington, Tacoma

Social Work Program

1900 Commerce Box 358425

Tacoma, WA 98402

hampsons@uw.edu

Alissa R. Ackerman, $\mathrm{PhD}$

California State University, Fullerton

Division of Politics, Administration, and Justice

aackerman@fullerton.edu

Acknowledgements: We wish to thank Lauren Lichty, Kyra Laughlin, Sorya Pao, and Shelby Weidmann for their generous assistance with this project. 


\begin{abstract}
This exploratory study brings together two lines of inquiry on 1) college campus-based responses to sexual and intimate partner violence among students, and 2) the characteristics, experiences and challenges unique to commuter students and commuter institutions of higher education. Using qualitative analysis of 14 in-depth interviews with campus personnel and focus groups with a total of 71 students on three commuter campuses in the Pacific Northwest, we offer a detailed description of the experiences and characteristics of commuter students as they pertain to sexual and relationship violence programming and prevention, the associated nature of commuter campus communities, and the resulting lack of visibility of the issue of sexual and relationship violence on commuter campuses. We conclude that creative, tailored approaches to prevention and response services on commuter campuses are needed to address the unique circumstances and challenges facing commuter campus students.
\end{abstract}


PUBLISHED IN JOURNAL OF INTERPERSONAL VIOLENCE - 3

\section{Sexual and Relationship Violence Prevention and Response: What Drives the Commuter Campus Student Experience?}

The focus of both public and academic discourse on the topics of campus sexual assault and intimate partner violence among college students has largely been on "traditional" four-year college campuses. This stands in stark contrast to the fact that the vast majority of undergraduate students in the U.S. are commuters, with approximately $85 \%$ of college students now living offcampus (National Center for Education Statistics, 2019). Given these trends, a robust discussion of the response to and prevention of sexual assault and intimate partner violence (IPV) on commuter campuses is needed. Because of the dearth of literature connecting the commuter campus experience to tailored violence response and prevention programs, basic descriptive information is needed regarding the unique experiences and characteristics of commuter students relevant to the delivery of violence-related programming. The purpose of this exploratory study was therefore to describe the dynamics associated with serving commuter campus students as they relate to the design and provision of sexual and relationship violence response and prevention services. Because we address both sexual assault and intimate partner violence among students, we use the term "sexual and relationship violence" for parsimony throughout this paper. Like Clark (2006), we define commuter campuses as undergraduate institutions comprised primarily of students who live off-campus.

\section{Campus Sexual Assault Literature: A Focus on "Traditional" Campuses}

Decades of research have consistently documented that about 1 in 5 women will experience sexual assault while in college (Cantor et al., 2017; Koss, Gidycz \& Wisniewski, 1987). Further, the recent Association of American University survey of 27 Universities found that over $10 \%$ of undergraduate women experience rape and $12.8 \%$ experience IPV while 
enrolled in college (Cantor et al., 2017). None of the oft-cited studies comprising this literature provides a clear picture of the degree to which prevalence rates are similar across residential and non-residential students. Indeed, a recent systematic review of campus sexual assault prevalence research noted that the vast majority of data is based on 4-year residential campuses, and that the few studies which may include non-residential college populations do not consistently disaggregate campus type in their findings (Fedina, Holmes \& Backes, 2018).

This dearth of commuter-campus research extends to studies of response and prevention efforts. To be sure, a focus on residential campuses is understandable given research that shows a correlation between residentiality and the prevalence of on-campus rape (e.g. Stotzer \& McCartney 2016). Further, U.S. campuses are beholden to Title IX policy which holds them responsible specifically for addressing sexual misconduct that happens in campus contexts or between members of the campus community; violence that happens off-campus, in commuter students' private lives may be less visible to campus systems or policies. Accordingly, much of the literature on the dynamics of violence on campus, particularly sexual assault, directly speaks to populations that are typically found on "traditional," four-year residential campuses, such as Greek life (e.g. Canan et al., 2018), and athletics programs (e.g. Stotzer \& McCartney, 2016).

Similarly, the explosion of research regarding campus-based violence prevention focuses largely on "traditional," residential schools. A recent review of systematic studies of sexual assault prevention programming (Vladutiu et al. 2011) indicates that "the effectiveness of university-based sexual violence prevention programs varies depending on the type of audience, facilitator, format and program content" (p. 81). Yet none of the review articles included in the Vladutiu et al. review discuss the unique features or needs of commuter campuses, or identify for what types of campuses their findings are most suited. The more recent, groundbreaking 
research around bystander-based approaches to sexual violence prevention on campuses is another area in which the unique considerations for commuter campuses are under-explored. Because participating campuses are often masked in published prevention program evaluations, recent reviews of the efficacy of bystander programming have also not been able to disaggregate results by type of campus (e.g. Jourilles et al., 2018), and many evaluated bystander models are implemented in settings specific to residential campuses such as residence halls (e.g. Gidycz et al., 2011) and fraternities (e.g. Foubert et al., 2011). Cares and colleagues (2015) offer an exception in their evaluation of the adaptation of Bringing in the Bystander to a "heavily commuter" campus in an urban setting. While the program was successful at attitudinal change among female participants on the new campus, it was less successful than the residential-campus implementation at outcome change among male students. The authors note that even more carefully tailored work may be needed to address the unique features, considerations, and culture of a new campus implementation site (Cares et al., 2015). Similarly, Vladitiu et al. (2011) conclude that colleges and universities must attend to empirical evidence regarding key ingredients of effective prevention when designing and implementing programming. Matching violence response and prevention activities to commuter campus contexts, however, requires a better understanding of commuter students and institutions.

\section{Commuter Students and Commuter Campuses}

In the absence of violence-specific information from commuter campuses, we turn to general, but also sparse literature on the nature of commuter campuses as institutions and commuter students as individuals. Donaldon \& Townsend (2007) point to a huge growth in what they call "adult undergraduate students" in higher education, which they define as students over the age of 24 . The authors note, however, that despite these changes in higher education, 
"scholars have paid little attention to adult students' presence and their impact upon nonprofit higher education" (p. 28). While "non-traditional" (older, first generation, etc.) students, students of color, and students with fewer financial resources are more likely to attend commuter or community college campuses (Horn et al., 2006), commuter student populations are understudied on both non-residential and residential campuses.

Nonetheless, a handful of recent publications hint at common needs and concerns of commuter students. Jacoby (2015) notes that these include transportation issues such as parking, traffic, and vehicle maintenance, as well as what she calls "multiple life roles." This latter concern can include the fact that many commuting students work full time or have family or caregiving commitments. These multiple demands on students' time then create barriers to connecting to support networks on campuses and feeling a sense of belonging to the campus community (Jacoby, 2015). Living off-campus is associated with students focusing more of their time and attention on competing priorities such as work which may hinder their ability to engage on campus (see for review, Burlison, 2015) and may leave them feeling isolated and lacking "well-defined social communities" (p. 4; Braxton et al., 2013). In a conceptual discussion and literature review of issues specific to urban commuter students, Clark (2006) notes that commuter students may feel more isolated and less empowered to proactively seek out supports than residential or "traditional students." As Jacoby (2015) points out, meeting the needs of commuter students either on more traditional campuses or primarily commuter campuses will require a complex set of tactics that meet the diverse needs of this heterogeneous population. Given these barriers to campus-based supports, commuter students may, by extension, have difficulty accessing violence prevention programs and/or relevant campus-based services in the aftermath of sexual or relationship violence. To date, however, we are unaware of research 
specifically examining commuter students' experiences with campus-based sexual and relationship violence service systems.

\section{Summary and Purpose of Study:}

In summary, two parallel but largely non-intersecting literatures have developed that examine 1) the prevalence of sexual and intimate partner violence among college students and accompanying promising institutional responses to this issue, and 2) the characteristics, experiences and challenges unique to commuter students and commuter institutions of higher education. Given the importance of tailoring violence response and prevention programming to commuter campuses, the purpose of this initial exploratory study is to bring together these lines of inquiry. To this end, we conducted focus groups and interviews with students and personnel on three commuter college campuses. Our aim was to describe the characteristics, challenges, and experiences of commuter students that hold implications for the design of sexual and relationship response and prevention programming on these primarily non-residential campuses.

\section{Method}

\section{Overview and Sample:}

Data were collected from respondents on three campuses in the Western U.S. which are attended primarily or exclusively by commuter students. All campuses were mid-sized (30006000 students), and two had residential facilities for 5-10\% of their respective undergraduate student populations. Campuses were situated in urban, semi-urban, and suburban geographic areas respectively, and all had emerging support systems in place for students. For example, all campuses had robust counseling centers, campus safety, and equity/inclusion programs, but other centers or services (such as health centers, women's centers, etc.) were emerging or non-existent. 
Because our research questions were deeply exploratory in nature, our methods were guided by a constructivist perspective on knowledge production. As Charmaz, (2000) notes, a constructivist approach acknowledges the mutually created nature of knowledge and understanding, and honors participants' interpretations of the meaning of their experiences. More specifically, we hoped to gain an understanding of the variety of ways in which commuter campus stakeholders (students and personnel), understood, experienced, and articulated the intersections between their lives, their campus contexts, and the ways that sexual and relationship violence are addressed in those contexts.

Data were therefore collected via focus groups and individual interviews, data collection methods well suited to eliciting the experiences and meanings of subjects within a constructivist perspective (MacKenzie \& Knipe, 2006). Focus groups were conducted to solicit undergraduate student perceptions, and individual interviews were conducted with staff and administrators whose roles intersected with student support and/or Title IX-related services and procedures. Focus groups were conducted by the authors and trained graduate and undergraduate research assistants, and interviews were conducted by the authors. The combination of focus groups and interviews across campus stakeholders was selected as an over-arching data collection approach to provide varying viewpoints about services and systems already in place, their accessibility and visibility, and challenges or strengths associated with accessing (students) or implementing (personnel) current programming. Additionally, by speaking with both students and personnel, we hoped to identify areas of overlap as well as disagreement between these constituencies regarding the robustness of and challenges associated with violence response systems. Finally, we elected to include staff and administration because of their campus-level view of services and 
policies; faculty were not included because of the challenge of recruiting faculty with sufficient exposure to campus-wide violence-related systems.

Data for these analyses are from a final sample of 71 students aged 18-37 $($ mean $=22.9)$ across 11 focus groups. Of these, $73 \%$ identified as female, $24 \%$ as male, and $3 \%$ as non-binary. Three participants (4\%) reported their race as African American, $12(17 \%)$ as Asian or Asian American, 9 (13\%) as Latinx, 2 (3\%) as "Middle Eastern," 8 (11\%) as multi-racial, and 37 (52\%) as White. Demographic data were not collected from personnel interviews due to concerns related to confidentiality and identifiability. Fourteen interviews were conducted across the three campus locations. Participants were exclusively administrators and staff housed in positions that serve the campus as a whole. Personnel represented a range of offices including student conduct, counseling, equity and diversity, residential life, student advocacy, student affairs, and instructional support services. Participant recruitment procedures used in the study were reviewed and approved by the [authors' institution] Internal Review Board.

\section{Procedures}

Student focus groups. Students were recruited to the focus groups in two ways. First, the authors made presentations in a variety of classes on each campus; classes were selected to be diverse in terms of substantive area, lower vs. upper division, and possible gender and race composition among students. The study was introduced as an opportunity to provide feedback about perceptions of violence response and prevention programming on campus, and to share ideas for enhancing it. Eligibility included being 18 or older and a full or part time undergraduate student on the campus and interested students could sign up for a pre-scheduled focus group after the presentations. Information about the study was also disseminated via flyers and emails on each campus, and potential participants contacted the research staff to sign up for a focus group. 
Groups were held on campus, lasted 90 minutes, and were digitally recorded. They were facilitated by teams of two (always inclusive of at least one of the authors and a student research assistant). Students participated anonymously and received a $\$ 25$ gift card as an acknowledgement of their time.

Personnel interviews. Personnel perceptions of campus response systems were collected via individual interviews. This approach was selected both to ameliorate logistical challenges of convening busy staff and administrators, and to enhance the degree to which participants felt they could be candid. Research staff worked with Title IX - related staff and/or chairs of sexual assault task forces on each campus to identify staff and administrative stakeholders with experience or responsibilities related to some aspect of addressing violence. Potential participants were then invited to participate via email, and the invitation was framed as an opportunity to describe the assets and challenges on commuter campuses related to implementing sexual and intimate partner violence response and prevention programming. Interviews occurred primarily over the phone, lasted between 30-60 minutes, and were digitally recorded and professionally transcribed. Participants received a $\$ 25$ gift card in recognition of their time.

\section{Measures}

Focus groups were facilitated using a semi-structured interview guide. Each group began with an overview of guidelines for discussion, and a reminder that the purpose of the groups was not to solicit personal experiences of sexual assault or intimate partner violence, but to share their perceptions of and ideas for the campus response to violence. We also explicitly framed the study as pertaining to commuter students' experiences and perceptions with a goal of enhancing system responsiveness specifically for non-residential students. Question domains included perceptions of student life on campus, how sexual violence and IPV impact students' lives, 
available services and their inclusivity/accessibility, and campus-related supports and barriers to accessing services and prevention programming. Sample questions included, "From your perspective talk a bit about what it is like to be a [x campus] student;" "From your perspective, in what ways is interpersonal violence an issue or problem for students at [x campus];" "What resources exist on this campus when students are impacted by sexual assault or IPV;" "What makes it hard or easy for students to access campus resources?"

Interviews with personnel also used a semi-structured interview guide with comparable domains and framing. Participants were asked to describe their role, and the current sexual and relationship violence-related policies and services on campus. Questions included but were not limited to, "In what ways does sexual violence like rape or other unwanted sexual experiences impact students at [x campus];" "What resources exist on this campus when students are impacted by sexual assault or IPV?" "What would you like to see done differently or in addition to what is in place already;" and "As you think about violence programming, what are the specific dynamics, strengths, or barriers that are created by serving a commuter student population?"

\section{Data analysis}

Data were analyzed by the first two authors using the qualitative software program Dedoose (version 8.1.8). Analysis proceeded in three phases. First, for transparency, tentative apriori sensitizing concepts were jointly identified by the authors based on ideas they repeatedly heard in focus groups and interviews - these included codes such as parking barriers, competing demands on students' time, and a lack of knowledge regarding service availability. These codes were identified in order to both acknowledge and bracket their potential presence, and minimize the impact of a-priori assumptions on the subsequent inductive data analysis process. Second, the 
team conducted basic thematic analysis using steps outlined by Braun \& Clark (2006) within whole responses to focus group and interview questions to identify initial specific codes. This highly inductive method was selected because of its fit with a constructivist approach (Braun \& Clarke, 2006), its flexibility and ability to accommodate a range of similar and differing perspectives among participants (Nowell, Morris, White \& Moules, 2017), and its utility with topics which are relatively unexplored to date (Hseih \& Shannon, 2005). Specifically, each of the first two authors coded 3 unique transcripts. As new codes emerged, defined here as small units of meaning holding implications for the guiding research question, these codes were vetted with the other researcher and added to the emerging code-book. No new code was added without both agreement by both analysts and a review of the original text from which the code was derived. Each transcript was then coded by a second coder, both to enhance accuracy and to examine previously analyzed transcripts for material related to new codes. This process was repeated until all transcripts were coded by both authors. The final, resulting codebook consisted of both the small number of a-priori codes identified (none of these were ultimately eliminated), and codes that emerged through analysis.

Third, once all transcripts were coded and the codebook was finalized, the team again followed steps outlined by Braun \& Clarke (2006) to distill larger thematic categories from the basic codes. Codes were first examined by the first author for overlap in thematic content. This occurred both by a grounded-theory informed constant comparative method of comparing meanings between each code, and through the use of the code co-occurrence feature within Dedoose which identifies codes that consistently appear together and are applied to the same textual excerpts. This allowed for the identification of codes that were potentially redundant and for collapsing them into themes, as well as to examine possible inter-relationships between 
themes. Generally, resulting themes centered on commuter student experiences as they pertained to violence programming. One initial code - conceptualizing student's relationships to “community" on commuter campuses, contained significant and diverse content. While we did not specifically ask participants to describe campus communities, this emerged as a common topic across focus groups. We therefore engaged in a second round of thematic coding to examine potential sub-themes within this content; the nature of campus communities became a larger category, with the five sub-themes described below. Further, several of the subthemes related to the nature of commuter campus communities were consistently co-coded with themes related to the characteristics of commuter students, thus surfacing the inter-relationships depicted in Figure 1. An initial distillation of themes and larger relationships was generated by the first author, and reviewed by research team members. Finally, we used the code application analysis feature within Dedoose, which creates a matrix of code applications within and across transcripts, to examine the degree to which each theme emerged primarily from students, personnel, or both, and across which campuses.

\section{Results}

Experiences of commuter students related to conceptualizing violence prevention and response systems on commuter campuses fell into three larger categories: 1) characteristics and concerns of commuter students themselves, 2) the nature of commuter campus "communities" and 3) a prevailing notion that sexual and relationship violence are somewhat "invisible" issues on commuter campuses, particularly from the perspective of students. Each of these first two categories had several subthemes, which are summarized below and captured in Figure 1. Although student participants discussed their perceptions of violence-related programming on campuses, consistent with the theme of the invisibility of the issue of violence on campus, most 
also reported having little exposure to available services or prevention education. Thus, many of the below subthemes represent participants' efforts to use their own, more general experiences as students to point out implications for campus programming, including violence-specific programming. The implications of these results are addressed in the Discussion section.

\section{Commuter Student Characteristics.}

Five characteristics and concerns of commuter student populations were identified as salient to conceptualizing violence prevention and response systems on commuter campuses. First, consistent with extant literature, both students and campus personnel frequently described commuter students as having complicated lives. This characteristic was mentioned in 9 student focus groups and 11 personnel interviews. Participants noted that commuter students often work full or part time, have families and other caretaking responsibilities, are often significantly financially under-resourced, and may have other barriers to participating in campus activities or accessing campus services on a regular basis. One student noted, "I work; I'm a mom; I'm a wife. I don't have time to come back to campus and do all these other things." (Campus 1). An administrator on the same campus echoed, "Our student population... is a little bit older, average age 26. So, people are coming and going, and families and working. It's hard to get their attention beyond academics at times." An administrator on campus 3 explained the challenges of conceptualizing services and programming that fits commuter student needs and schedules:

A lot of commuter students are... either traveling by bus or car to even get here on campus and then often times wanting to leave to avoid rush hours to get back where they're going, where they're living, or having jobs that are elsewhere, not on campus. So - needing to leave to get to their job... or for those students who have their own families, children of their own... Where when students come to residential campuses, they're from anywhere from two states away from family of origin so there's no more expectation from that family that you contribute to the family. Where for commuter students, that's still a high, high expectation." 
Relatedly, parking and travel were barriers to campus engagement. Although arguably a facet of students' "complicated lives" as discussed above, parking and travel were described as separate, and significant impediments to participating in campus events or services beyond academic requirements. On two of the included campuses, students had to pay for parking or devise solutions for commuting or walking significant distances to avoid parking costs (mentioned in 5 focus groups and 4 personnel interviews). Attending anything other than class on campus compounds students' financial burden through increased parking costs or extra trips to and from campus, as noted in this student's comment, “... if you have to plan ahead for how much money you're going to have to pay here for your parking, people are more likely to pay to cover their classes and not stay after for a club or some sort of student engagement." (Campus 2). Some students noted that parking cheaply created safety concerns, and was prohibitive for attending evening events. Navigating the logistics of travel impacts other aspects of students' campus experiences and peer relationships, as evidenced in the following student comment, "After class there's no conversation with your peers, it's 'get out to your car as fast as you can to beat the traffic.' So to get people to participate in extracurricular things, they have to pay to be here, they had to pay to fight the traffic - it's rough." - Campus 2 student

Respondents from all three campuses also described students as coming from

geographically diverse and dispersed communities (this characteristic arose in 6 focus groups and 6 personnel interviews). Clearly related to the expense and time involved in travel and parking, this characteristic also created unique barriers. Each campus in the project drew students from multiple surrounding counties, each with different sets of community resources, local cultures, and challenges. Both student and personnel participants noted that students who travel from neighboring counties or cities may not see either campus itself or the geographic area around campus as part of their community or home. One student on campus 1 noted, "There was 
a student in one of my classes...[who] had a two-hour drive in every day, so people come in long distances to be here. So, I think "community" is really dependent on who is receiving the information." Relatedly, a Campus 1 focus group discussion centered on the challenge of doing services-related outreach and campus-community partnership building with so many neighboring cities and counties to select from: "Well, which community are we going to reach out to? We've got [City 1, City 2, City 3, City 4, City 5], the surrounding cities around [City 5]...how do we... what resources are we going to use?" A campus 3 administrator echoed this noting, "We're trying to make connections with resources in [county one and county two], and that's a challenge. It's just a bigger catchment area."

Next, participants on all campuses noted both the strengths and challenges associated with the intersectional diversity of the student bodies. This characteristic was discussed in 5 focus groups (from 2 campuses) and 6 interviews (across all campuses). When students discussed this theme, it was only as an asset. Student respondents described the diversity of the student body as creating a sense of belonging and welcome, and several students noted that they see themselves reflected in their classmates. A student on Campus 3 noted,

"What I like about this campus the most is the diversity and amount of, different cultures, different types of people, different backgrounds... which, in a way, just make it so that I don't have to feel that I'm different... I feel blend[ed] in and very comfortable."

Diversity in the student body was connected with creating a sense of community on campuses, which for some students was facilitated by the opportunity to join diverse clubs and affinity groups. Describing the range of student organizations available, one student noted, "I've gotten pretty involved, and so, I have found my community. I feel like there's a huge community here at [Campus 3], but I also feel like there's lots of small communities." Although students on two campuses commented on the diversity inherent in the student body, focus groups respondents 
across all three campuses commented that the staff and faculty on these campuses do not necessarily reflect that diversity, which created a barrier to service accessibility. In a typical comment, a student on campus 2 noted, "I don't see as much diversity in our faculty as I do in the students... and the counseling center is also kind of like that, where there's a little bit less diversity." Intersectional diversity thus facilitated connection among students, but from students' perspective, this strength was not replicated among staff or at a structural level on campuses.

When this theme arose from personnel interviews, intersectional diversity was presented as more of a complexity for service planning and provision. While staff and faculty universally described their campuses as committed to serving the diverse range of needs among students, respondents also described challenges in meeting this goal. Identified challenges included the need to make all services and programming flexible enough to meet the needs of students of different ages, cultural backgrounds, religious affiliations, etc., as well as simply the number of supports required to meet the full range of student needs. One administrator noted,

"On a commuter campus what we see is that we have a lot of people that maybe have very different and sometimes competing needs, that we're trying to respond to or get attention around... and it makes it interesting, and I think a bit challenging with also the limited space available itself, it feels like sometimes people are fighting, not fighting, but really competing with one another to have their needs met. Because there aren't enough resources for everyone and every diverse need." (Campus 3)

Some personnel noted that this creates a barrier to prioritizing issues of violence over other important student needs, as well as to finding ways of addressing violence in culturally flexible and multifaceted ways. Going further, a staff member on campus 2 pointed out that the specific violence-related needs of underrepresented students may not come to the forefront even on diverse commuter campuses because of concerns about stereotyping,

"there's still that pressure not to say anything that would provide a negative image of your identity... because if you already have a stereotype of queer individuals or 
transgender individuals or Muslims, or Black or Latinx individuals, I don't want to add to that by talking about intimate partner violence because you're going to use that against me and my people. So we're not gonna go there."

Finally, respondents on all campuses reported the perception that interpersonal violence is a prevalent problem among commuter students, but that victimization experiences happen mostly off-campus, in students' private lives. This theme was mentioned in eight focus groups and six personnel interviews. Participants across focus groups and interviews noted that intimate partner violence and sexual assault can occur both on or off-campus, and indeed gave several examples of on-campus incidents they had witnessed or heard about. Overall, however, respondents suggested that, given the relatively small amount of time most commuter students spend on campus, experiences of violence were more likely to stem from people's private lives. A student on Campus 1 stated, "We spend hours of our day here and then we go on with our lives outside in the community and that's where these things [violence] happen." These could include experiences that occurred either prior to or since enrollment, as noted by one Campus 3 administrator, "A lot of the things that folks... have reported are things that happened to them historically. Things from childhood... or intimate partner violence."

Some focus group participants suggested that because victimization is likely to occur outside of the campus context, students may assume that this makes them ineligible for accessing on-campus counseling. Other students and some personnel noted that campus response systems are structured around Title IX considerations and are more tailored to addressing violence between campus community members, thereby potentially reducing the extent to which services adequately address preexisting or off-campus trauma. Describing attempts to get support after an off-campus assault, one participant on Campus 3 noted, “...so the only option for me was student conduct. But since I wasn't assaulted on campus and I wasn't assaulted by someone within the 
system, it seemed like that wasn't a resource for me." Nonetheless, when the issue of the impact

of victimization was mentioned, participants noted the significant personal and educational effects of trauma, such as in the following statement from a Campus 3 student:

"I agree that its mostly the off-campus kind of violence or assault... and I think it impacts [the person] tremendously. It can literally change and reformat the way that you think... and that plays a huge role in stress levels, and how you prioritize your time. Because people get to the point where they're so stressed, they're so like - emotionally unstable or hurt, that they prioritize that over education, because they're like, 'I gotta think about myself before I think about my degree.'”

Because violence may be happening in students' private lives rather than on campus, there may be something of a disconnect between existing campus response systems and the reality of the ways in which violence shows up in and impacts commuter students' lives and educational goals.

\section{Commuter Campus Communities}

As noted in the analysis section above, several themes emerged that sat at the intersection of aforementioned student characteristics and that collectively describe the dynamics of commuter campus communities. Each of these themes, as they intersect with one another, hold implications for how the nature of "community" on campus can be leveraged for or can create barriers to creating violence response and prevention systems. We have organized our analysis of the implications of these intersecting themes into four subthemes, represented in Figure 2 as having an overlapping and mutually constitutive relationship.

First, the most prevalent idea emerging at the nexus of commuter campus student characteristics was that cohesive "community" on commuter campuses is hard to come by. This theme was described in a variety of ways by both students and personnel; some aspect of this theme came up in every focus group or interview. Some participants expressed the notion that the busy nature of commuter students' lives meant that campus is viewed by students as simply the place they attend class for a few hours a day, and not as their "community." One student on 
Campus 1 noted, “...people are going to and from class - 'PCP-ers.' Parking, Class, Parking, that's what they do." Relatedly, several focus group respondents felt that campus is not always perceived as students' “community.” Students' brief interactions with campus and their busy, established, off-campus lives mean that they have or find community elsewhere; campus may not be on the radar as a source of "community" or support. A student on campus 2 noted, "One thing I feel about this campus... is because it's a commuter campus, people feel more like it's a job. I feel like you don't get that relationship with your fellow students and towards the campus."

Other participants, primarily students, noted that establishing a sense of community and belongingness on campus is possible, but is not universally accessible. Some students felt that the relatively small size of the campuses create the possibility for interconnectedness, running into people one knows, and a sense of belonging. As noted above, some students pointed to the diversity of the student bodies and clubs as fostering opportunities for connectedness. Others characterized belonging as a privilege not available to everyone. Students and personnel noted that students with multiple off-campus obligations or resource limitations may be less able to take advantage of involvement opportunities on campus, or to develop the kind of on-campus relationships that foster "community." A student on campus 2 felt that, "there's opportunities to feel like a community, but you have to kind of want it and pursue it yourself." Relatedly, a campus 3 participant noted that very few people on campus have the time to get involved, stating, "there's a core group of 100-150 students that are in every club." Collectively, these ways of describing the campus community coalesce around the notion that a cohesive sense of "community" is difficult to cultivate, and even if present, is not universally accessible.

In a separate but related subtheme, focus group participants on two of the three campuses noted that it is hard to make friends with other commuter students. This idea arose almost 
exclusively in focus groups and both overlaps with the aforementioned lack of a cohesive campus community and holds additional implications. Participants felt that the challenges associated with staying on campus or interacting with anyone outside of academic classes make it difficult to connect with each other and develop friendships. One campus 2 student noted, "Students won't talk to other students because they have to run out to their cars and we don't have really good clubs right now."

Yet - when asked to whom they would turn if they had concerns related to interpersonal violence, "friends" were some of the most commonly mentioned supports by participants across all three focus groups. Students across all focus groups noted that they rely on friends to get information about resources or events on campus. For example, describing to whom she would turn to get a sense of what supports might be helpful on campus, one campus 2 student stated:

"... if someone else that you know has already been there, and they're like, "Oh, yeah, you should go, they're really nice and supportive and it really helped me," especially having those personal experiences from people that I actually know, it makes you want to go so that you can feel better, too."

Similarly, an administrator on Campus 3 noted, “we've found there's a lot of word of mouth around the victim advocate... once a student comes in and has a positive experience, they've encouraged other friends... to reach out directly to the victim advocate." This contrast between viewing friends as resources, but also experiencing challenges making campus-based friends may mean that some students are further distanced from knowing about and being connected to campus-based resources and supports.

The third theme related to the nature of commuter campus "communities" emerged exclusively from focus groups. The limited points of contact that many commuter respondents reported having with campus often meant that students' first or only experiences with campus offices or personnel shape their expectations for what to expect from other campus entities - 
such as services related to sexual assault or intimate partner violence. As we discuss in more detail below, few respondents reported knowing about violence-specific resources on campus. Across focus groups, however, students indicated that they would anticipate having a similar experience with violence-related services as they'd had with other offices. Any element of the campus community might therefore become a defacto advertisement for the degree of responsiveness of violence-specific services. While this may be true on residential campuses as well, residential students may have more connections with different offices, residence halls, and individuals on campus and therefore multiple potential entrees into support or for receiving information about resources.

Basing expectations on initial points of contact played out in two directions in the focus groups. For example, responding to a discussion about willingness to reach out to campus-based violence services, one student on Campus 2 stated, "I haven't gone to counseling services, but when I go to academic advising I've always had very positive experiences... I got a good impression from the beginning... I would feel comfortable reaching out." In contrast, another student on this campus noted pessimism about the degree of campus responsiveness, stating,

"I was trying to seek help and every quarter I kept getting blocked from registering for classes, for example, and no one seemed to have been helping me. I had to do it all on my own... and so I got kind of discouraged from seeking counseling, or advising, for my own issues...."

Many focus group participants noted that faculty are the personnel they know best or interact with the most on campus. As a group, faculty may therefore be the most common first point of contact and entrée into supportive services for commuter students. Students were roughly split, however, in terms of how likely they would be to seek support from faculty when struggling with a barrier to academic success or participation (not necessarily exclusively related to violence). This split was similar to the dynamic described above, based on their previous 
experiences, and roughly corresponded to how responsive they anticipated faculty, and by extension, others on campus might be. For example, a student on Campus 1 noted that a professor outside her major went above and beyond to connect her with services and professional connections, concluding, “so, I feel like everyone's kind of welcoming” [emphasis ours]. In contrast, another focus group participant on Campus 2 reported that a faculty member's failure to notice harassment happening in class made her pessimistic about the utility of reaching out to faculty or others for help: "I felt like the professors had to know what was going on. It was just too obvious... they were trained to look out for this, and I was incredibly disappointed that somebody with a PhD who proclaimed to fight for women's rights couldn't figure out that he had 18 sexist kids in his class." For better or worse, then, many commuter students' perceptions of the larger campus, and their knowledge of available resources may be related in part to their relationships with instructors, and the instructors' skill or knowledge around campus resources. The previous three subthemes contribute to our final "community" - related subtheme, which is that for many students, the campus community is not a relevant source of support for personal issues. Focus group participants on all three campuses expressed the notion that some students perceive campus as "for class only." This was succinctly communicated by a student on Campus 3 who noted, 'I've met people who have the belief that the university is a place you come to be educated, and that's it. Some people don't associate the university as a potential resource for them." Students' busy lives and the challenge of making connections on campus may mean that campus-based violence services are simply not on students' radar. Another student on Campus 2 linked this notion to students' experience of violence in their private lives,

"I hate to keep bringing up the community building part of it, but I think that's really important, because I think that somebody that is suffering from [violence] that didn't happen on campus, then they wouldn't connect it, like would not go to 
anybody on this campus. So, if it happened off-campus, why would you go to a counselor on campus?"

Finally, a staff member on campus 2 noted that students' geographic dispersion often means that their local community is a more logical source of support, "folks... are in that commuter campus population where doing something in [nearby city] or up the hill or something, is a better fit for them just based on their geographic kind of need."

\section{Issue of Violence not Visible on Campus}

Finally, a strong overall theme emerged across all campuses that sexual violence and

intimate partner violence are not visible issues on campus. This theme is closely connected to both the experiences of commuter students and to the resulting nature of commuter campus communities. Students, in particular, noted that they rarely see the issue overtly addressed on campus, and focus group participants in 10 of the 11 focus groups on all campuses struggled to name violence-specific campus resources. Typifying this was a statement from a Campus 3 student, "If I were in that situation I don't know where I would go." About half of students noted that they were not sure where a student would go on campus if they were impacted by violence; others stated they weren't sure, but knew where to find relevant flyers or webpages. One student on campus 2 stated, "I get the security alerts from the [flagship campus] for robberies and sexual assaults and stuff like that, but never from [this campus]. I've never heard it talked about in classes or anything. To me, it seems like a non-issue... I haven't heard anything from [this campus]." Students who were more familiar with campus response systems were often student employees, one the few residential students on campus, or members of campus clubs; "I know as a student leader, we go through a lot of trainings through the year," noted one Campus 1 student. Administrative personnel and staff who were interviewed were naturally more familiar with the campus structures available to support survivors of violence or to respond to official 
reports, and saw their campuses as striving to be responsive. For example, an administrator on campus 1 stated, "I think that we take it very seriously. We want to make sure that if there is a situation going on that we don't just brush it off... we look at it as if there is an opportunity for us to be of assistance to the student, we will step up and do it." Personnel also noted, however, that they worry that students are not adequately informed about the availability of services, such as this staff person on Campus 3, “I don't think there's enough visible resources. I don't think student know enough about what folks offer to seek them out." Only one staff member expressed pessimism about their campus' overall commitment to addressing violence, suggesting that there can still be pressure to avoid the issue to protect campus image, "That's still under the surface 'keep it in back rooms.' That's beginning to change, but yeah - it's still seen as kind of a twice a year issue - October is DV month, and April is sexual assault awareness month."

\section{Discussion}

This exploratory study surfaced interconnected themes regarding the characteristics and experiences of commuter students and resulting dynamics on commuter campus communities that hold implications for how sexual and relationship violence programming are adapted to these spaces. On a basic level, our findings regarding commuter students echo previous scholarship (e.g. Nelson et al., 2016) showing the incredible diversity of identities, needs, and challenges for non-residential students, including competing roles and demands for their time, prohibitive commutes and transportation issues, and diverse geographic communities of origin. Given the strong perception among our participants that many students are also carrying private trauma with them to campus, these findings underscore the need to adapt commuter campus violence-related systems to allow for a flexible responsiveness to the diversity of student needs. 
More pointedly, the experiences and characteristics of commuter students coalesced into specific themes related to the nature of commuter campus communities. Overall, many of the participants in our sample had difficulty accessing or establishing a sense of community on the campuses reflected here. Therefore, violence response and prevention programming efforts that attempt to leverage students" notion of "community," or that rely on on-campus events may miss the mark in terms of resonating with or reaching a broad swath of commuter students. These findings are also troubling, given the extant literature on the importance of community on college campuses for student retention and success. Evidence suggests that the degree to which students ascribe meaning to their formal and informal interactions within their higher education setting is related to academic persistence (e.g. Wetzel et al., 1999). Our findings indicate that a sense of community may also be important for the success and relevance of sexual and relationship violence response and prevention efforts on commuter campuses. Where students indicated a low sense of connection with their campus community, they did not see campus as a place to go for help and support when they experience trauma, despite the fact that trauma may impact their educational pursuits.

The relatively low visibility of sexual and relationship violence as an issue on campus may only serve to compound this disconnect. Our findings suggest a potential mismatch between available resources and their actual visibility to students, or at least between the personnel perception of the available support system, and students' perceptions of its relevance. The perceived lack of attention to violence on campus also appeared to be both an outgrowth of and in a reciprocal relationship with student characteristics and campus community themes (See Figure 1). As noted above, the challenges associated with fostering a sense of community and marshalling the resources needed to address the broad array of student needs may make it 
difficult for violence response and prevention to surface as a priority. This can then exacerbate the student perception that campus is not a place to seek support for violence-related experiences. Students of color and other under-represented groups may be additionally or particularly reluctant to avail themselves of existing services because of a lack of representation among staff, and, for some, concern about exacerbating negative stereotypes. Collectively, then, this suppression of the true level of violence-related support needs among students only further perpetuates the challenge of making violence response systems a priority and justifying the commitment of sufficient resources to address the problem. Interrupting this cycle of invisibility requires both calling explicit attention to the magnitude of the impact of violence on commuter students' educational pursuits and devoting resources to designing response systems that account for the complexities of non-residential students' lives.

\section{Implications}

Accordingly, we suggest initial implications for highlighting sexual and relationship violence as an issue on commuter campuses, as well as for adapting response and prevention programming. Commuter campuses may benefit from learning about and making visible the ways that commuter students and their educational aspirations are impacted by violence. The proliferation of sexual assault prevalence and climate surveys such as those summarized in the AAU report (Cantor et al., 2017), have yet to be as broadly applied to commuter and community campus settings. We recommend augmenting existing climate surveys with questions regarding off-campus and even lifetime victimization and trauma experiences, feelings of community and belongingness on campus, commuter-specific barriers to help-seeking, and perceptions of the inclusiveness of resources. Capturing data on these factors may help commuter campuses to assess the sufficiency and relevance of their current response and prevention programming as 
well as the degree to which students view campus as a "community" in which they can receive support. Adapting and implementing climate surveys and/or environmental assessments of available needs and services may help to both elevate the urgency of addressing sexual and relational violence vis a vis other issues and to understand the unique needs on each commuter campus community.

The notion of "community" on non-residential campuses as it relates to services advertising and prevention may also need to be creatively re-imagined. Commuter campuses likely have multiple internal "communities" as well as ties to external geographic communities, all of which are potential avenues of support to students. Reaching students may require multiple and simultaneous strategies that, given students' busy lives and parking/travel barriers, engage students in campus spaces they are in anyway - the parking lot, class, and the pathways inbetween. These strategies might include ubiquitous messaging on digital reader boards, on flyers in bathroom stalls, in syllabi, on parking meters, and through face-to-face education during class time. Event-based prevention or awareness building may not be as effective for commuter student populations, but if used, may need to include child care and parking reimbursement resources in order to attract participation.

Student participants in this study appeared to interact with fewer points of contact on campus, noting that faculty are often the personnel they know best and interact with most. Despite mixed reports regarding willingness to confide in faculty, it appears that faculty may be the first point of contact for many students who are struggling. To adequately address the needs of non-residential students regarding sexual and relationship violence on commuter campuses it is therefore important that faculty be trained to be able to convey that sexual and relationship violence are issues the campus cares about, to effectively respond to disclosures, and to provide 
service referrals for students who seek out assistance from them. "Friends" are also highlighted as an important first point of contact for students experiencing interpersonal violence, despite the noted difficulty with forming friendships on commuter campuses. Peer-to-peer response and prevention training that equips students to be spokespeople and ambassadors for campus-based support systems may be another good use of resources on commuter campuses.

\section{Limitations}

Limitations in the approach of this study include the small number of campus contexts represented and the fact that all campuses are in one geographic region of the U.S. The characteristics of these campuses may not extend to similarly situated campuses in other regions, or to different types of non-residential schools, including 2-year community colleges. Focus group methodology also comes with limitations, including the risk that talkative group members' perceptions are over-represented in the discussion as well as the challenge of assessing degrees of agreement or disagreement within groups as a whole. We attempted to mitigate this challenge by regularly checking for agreement and encouraging quieter voices in the room. Finally, the voices of some students and personnel may be missing or under-represented here, particularly those of faculty as well as students of color and men.

\section{Conclusion}

This exploratory study offers an initial in-depth look at the experiences of commuter college students that hold ramifications for the provision of sexual and relationship violence programming on non-residential campuses. We find that commuter campus students have complicated lives that are not centered on their campus, and thus the communities that develop on or around commuter campuses can be very different to those on more "traditional" campuses. Moreover, the characteristics of commuter campus students, coupled with the uniqueness of 
commuter campus communities, seem to contribute to a culture where explicit attention to the issue of violence is largely invisible on these campuses. These dynamics on commuter campuses have important implications for violence prevention and response programming, which is currently designed with the traditional campus model in mind. We offer suggestions above for improvements to the design and implementation of such programming with commuter campus students in mind, but we also recognize that more research is needed on the design, implementation and effectiveness of sexual assault and relationship violence prevention and response programming on commuter campuses. 


\section{References}

Braun, V. \& Clarke, V. (2006). Using thematic analysis in psychology. Qualitative Research in Psychology, 3 (2), 77-101.

Braxton, J. (2013). Rethinking college student retention (First ed., Jossey-Bass higher and adult education series). San Francisco, CA: Jossey-Bass.

Burlison, M.B. (2015). Nonacademic commitments affecting commuter student involvement. New Directions for Student Services, 150, 27-34.

Canan, S., Jozkowski, K., \& Crawford, B. (2018). Sexual assault supportive attitudes: Rape myth acceptance and token resistance in greek and non-greek college students from two university samples in the U.S. Journal of Interpersonal Violence, 33, 3502-3530.

Cantor, D. B. Fisher, S. Chibnall, R. Townsend, H. Lee, C. Bruce, G. Thomas. (2017). Report on the AAU campus climate survey on sexual assault and sexual misconduct. Rockville, M.D.: Westat.

Cares, A.C., Banyard, V.L., Moynihan, M.M., Williams, L.M., \& Stapleton, J.G. (2015). Changing attitudes about being a bystander to violence: Translating an in-person sexual violence prevention program to a new campus. Violence Against Women, 21, 165-187

Charmaz, K. (2006). Grounded theory: Objectivist and constructivist methods. In N.K. Denzin \& Y.S. Lincoln (Eds). Handbook of Qualitative Research (2 $2^{\text {nd }}$ Ed), pp. 509-536. Thousand Oaks: Sage Publications.

Clark, M.R. (2006). Succeeding in the city: Challenges and best practices on urban commuter campuses. About Campus, July-August: 2-8.

Donaldson, J.F., \& Townsend, B.K. (2007). Higher education journals' discourse about adult undergraduate students. The Journal of Higher Education, 78, 27-50. 
Fedina, L., Holmes, J., \& Backes, B. (2018). Campus sexual assault: A systematic review of prevalence research from 2000 to 2015. Trauma, Violence, \& Abuse, 19, 76-93.

Foubert, J., Brasfield, H., Hill, B., \& Shelley-Tremblay, S. (2011). The men's program: Does it impact college men's self-reported bystander efficacy and willingness to intervene? Violence Against Women, 17. 743-759.

Gidycz, C., Orchowski, L., \& Berkowitz, A. (2011). Preventing sexual aggression among college men: An evaluation of a social norms and bystander intervention program. Violence Against Women, 17(6), 720-742.

Horn, L., Nevill, S., \& Griffith, J. (2006). Profile of undergraduates in U.S. postsecondary education institutions, 2003-04: With a special analysis of community college students. Statistical analysis report (NCES 2006-184). Jessup, MD: U.S. Department of Education. Hsieh, H. F., \& Shannon, S. E. (2005). Three approaches to qualitative content analysis. Qualitative Health Research, 15, 1277-1288

Jacoby, B. (2015). Enhancing commuter student success: What's theory got to do with it? New Directions for Student Services, 150, 3-12.

Jouriles E.N., Krauss, A., Vu, N.L., Banyard, V.L. \& McDonald, R. (2018). Bystander programs addressing sexual violence on college campuses: A systematic review and meta-analysis of program outcomes and delivery methods. Journal of American College Health, 66, 457-466.

Koss, M. P., Gidycz, C. A., \& Wisniewski, N. (1987). The scope of rape: Incidence and prevalence of sexual aggression and victimization in a national sample of higher education students. Journal of Consulting and Clinical Psychology, 55(2), 162-170. 
MacKenzie, N. \& Knipe, S. (2006). Research dilemmas: Paradigms, methods, and methodology. Issues in Educational Research, 16 (2), 193-205.

National Center for Education Statistics (2019). Profile of Undergraduate Students: Attendance, Distance and Remedial Education, Degree Programs and Field of Study, Demographics, Financial Aid, Financial Literacy, Employments, and Military Status: 2015-16. Washington D.C.: U.S. Department of Education.

Nelson, D., Kaustav, M., Sype, G. E., \& Mackie, W.(2016). An analysis of the relationship between distance from campus and gpa of commuter students. Journal of International Education Research, 12(1), 37-46.

Nowell, L.S., Norris, J.M., White, D.E., \& Moules, N.J. (2017). Thematic analysis: Striving to meet the trustworthiness criteria. International Journal of Qualitative Methods, 16, 1-13.

Stotzer, R., \& Maccartney, D. (2016). The role of institutional factors on on-campus reported rape prevalence. Journal of Interpersonal Violence, 31(16), 2687-2707.

Vladutiu, C., Martin, S., \& Macy, R. (2011). College- or university-based sexual assault prevention programs: a review of program outcomes, characteristics, and recommendations. Trauma, Violence, \& Abuse, 12(2), 67-86.

Wetzel, J., O'Toole, N., \& Peterson, D. (1999). Factors affecting student retention probabilities: A case study. Journal of Economics and Finance, 23(1), 45-55. 
Figure 1. Themes and subthemes related to sexual and relationship violence response and prevention on commuter college campuses.

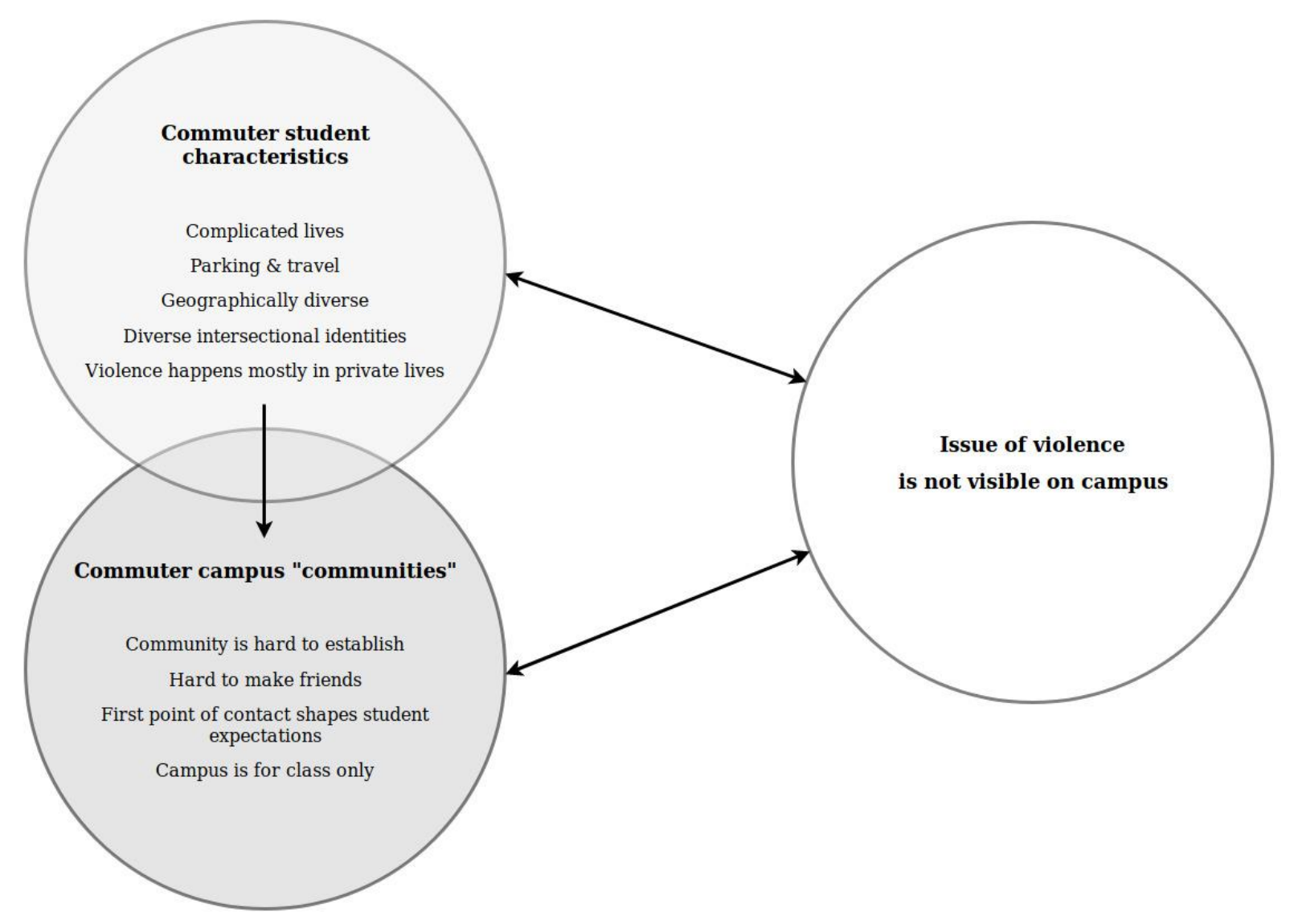

